\title{
Hyperglycemia Altered the Fate of Cardiac Stem Cells to Adipogenesis through Inhibiting the $\beta$-Catenin/TCF-4 Pathway
}

\author{
Xiaoming Zhang ${ }^{\mathrm{a}} \quad$ Ke Meng $^{\mathrm{a}} \quad{\text { Yujie } \mathrm{Pu}^{\mathrm{a}} \quad \text { Chao Wang }}^{\mathrm{a}} \quad$ Yingying Chen ${ }^{\mathrm{b}}$ \\ Linlin Wang ${ }^{b}$ \\ aDepartment of Basic Medicine Sciences, and Department of Emergency Medicine Sir Run Run Shaw \\ Hospital, Zhejiang University School of Medicine, Hangzhou; bepartment of Basic Medicine Sciences, \\ Zhejiang University School of Medicine, Hangzhou, China
}

\section{Key Words}

Diabetes • Cardiac stem cells $\bullet \beta$-catenin/TCF-4 • Adipogenesis $\bullet$ Lithium chloride

\begin{abstract}
Background/Aims: Hyperglycemia is an important risk factor for the most severe cardiovascular diseases in patients with diabetes. It has been demonstrated that cardiac stem cells (CSCs) play a pivotal role in the maintenance of cardiac homeostasis and regeneration. However, the mechanism underlying the influence of diabetes on CSCs remains unclear. This study demonstrated that hyperglycemia might promote adipogenesis in CSCs, which induces a decline in myocardial regeneration capability in diabetes. Methods: CSCs were isolated and cultured in high-glucose medium. The levels of $\beta$-catenin and TCF- 4 in CSCs were determined by immunofluorescence staining and western blot analysis. Adipogenic transcriptional factors and CSCs markers were also examined by flow cytometry and western blot analysis after adipogenesis induction. In addition, Oil Red $O$ staining was performed to investigate lipid droplet formation during adipogenesis induction with or without $\mathrm{LiCl}$, a potent activator of TCF/ $\beta$-catenin-dependent transcription. Results: High-glucose conditions inhibited nuclear translocation of $\beta$-catenin/TCF-4 and promoted adipogenesis in CSCs. After adipogenesis induction, expression of adipogenic transcriptional factors (PPAR, ADD1, and C/EBP $\alpha$ ) were increased $(P<0.01)$ and that of CSCs markers (c-Kit, Sca-1, MDR-1, and isl-1) were decreased $(P<0.01)$ in CSCs in the high-glucose group. Furthermore, lipid droplet formation was increased in CSCs cultured with high glucose, while $\mathrm{LiCl}$ attenuated lipid droplet formation in these CSCs $(P<0.01)$. Conclusion: These results demonstrated that hyperglycemia inhibited the $\beta$-catenin/TCF-4 pathway and promoted CSCs adipogenesis. Our findings suggest a new opportunity for future interventional strategie for abnormal myocardial regeneration and epicardial fat in patients with diabetes.




\section{Cellular Physiology Cell Physiol Biochem 2018;49:2254-2263

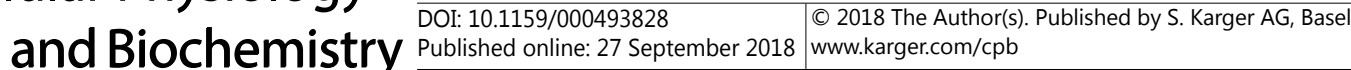 \\ Zhang et al.: Hyperglycemia Promotes Cardiac Stem Cell Adipogenesis}

\section{Introduction}

Hyperglycemia is an important risk factor for the most severe cardiovascular diseases that cause high morbidity and mortality in patients with type 2 diabetes $[1,2]$. It was reported that after myocardial infarction, diabetic patients were at increased risk of heart failure and cardiac structural changes such as left atrial enlargement over a 20-month follow-up period [3]. Furthermore, diabetes was associated with increased myocardial triglyceride content and epicardial fat $[4,5]$. Individuals at high risk of cardiovascular events have more periaortic fat than those at low risk, even after taking into account the body mass index [6]. Meanwhile, epicardial fat was negatively correlated with systolic and diastolic strain rates and heart failure $[7,8]$. However, the mechanisms underlying the decline in cardiac regeneration and increase in epicardial fat in diabetes remain unclear.

The adult heart has been traditionally viewed as a terminally differentiated postmitotic organ. However, the discovery of cardiac stem cells (CSCs), which have the capacity to differentiate into the various cardiac cell lineages, has dramatically changed the understanding of myocardial biology $[9,10]$. A single adult heart contains numerous CSC populations, which are divided into two types. One type of CSC population may include c-Kit ${ }^{+}$ cells, but this remains controversial; the other has been identified based on the expression of Sca-1, MDR-1, or isl-1. These CSCs can differentiate into myocardial cells, endothelial cells, and fibroblasts [11-13]. Although the resident CSC population is still unclear, with debate continuing, several types of resident cardiac progenitor (or stem) cells have been reported to reside in the adult heart [14]. These CSCs play a pivotal role in the maintenance of cardiac homeostasis and regeneration [15]. After heart injury, CSCs are stimulated to propagate and differentiate, then partially replace cardiomyocytes that have been damaged by ischemia or myocardial infarction [16-18]. However, the specific signal pathways of hyperglycemia that affect CSC differentiation, reduce myocardial regeneration capability, and increase the amount of epicardial fat in diabetes remain unclear [19].

Based on the findings above, we proposed the new hypothesis that high glucose may promote CSC adipogenesis, thus contributing to the low myocardial regeneration capability and high epicardial fat content in patients with diabetes.

\section{Materials and Methods}

\section{Animal studies}

The experimental procedures were approved by the Animal Ethics Committee of Zhejiang University (Hangzhou, China) and were performed according to the National Institutes of Health Guide for the Care and Use of Laboratory Animals.

\section{Isolation of CSCs and high-glucose treatment}

CSCs were isolated from the hearts of 1- to 3-day-old neonatal Sprague-Dawley rats as we described previously [20, 21]. CSCs at cell passage 1 were evaluated by flow cytometry using the Becton-Dickinson FACSCaliber (BD Bioscience, San Jose, CA) with 10, 000 events collected to confirm the cells were CSCs. CSCs were incubated with fluorochrome-conjugated primary antibodies against typical markers of cardiac resident stem cells, including c-Kit ${ }^{+}, \mathrm{Sca} 1^{+}, \mathrm{MDR}-1^{+}$[22], and Isl-1+ [23], as well as antibodies against hematopoietic lineage surface marker CD34 and endothelial lineage surface marker CD31. Isotype controls were run for each immunosubtype. A negative control was used to avoid false-positive results due to the fluorescent secondary antibody on the cells by fluorescence-activated cell sorting.

CSCs then were exposed to glucose (9000 and 18, $000 \mathrm{mg} / \mathrm{L}$ ) diluted in Iscove's modified Dulbecco's medium (IMDM) containing 10\% fetal bovine serum (FBS) for $72 \mathrm{~h}$. Mannitol (9000 and 18, $000 \mathrm{mg} / \mathrm{L}$ ) was used as a control with the same osmotic pressure. CSCs were washed twice with phosphate-buffered saline (PBS) and harvested for nuclear fractionation and western blot analysis.

\section{$\beta$-Catenin and TCF-4 protein nuclear fractionation}

CSCs were washed twice with PBS for 1 min and fractionated into cytoplasmic and nuclear fractions using nuclear and cytoplasmic extraction reagents (Beyotime Institute of Biotechnology, Shanghai, China). 


\section{Cellular Physiology Cell Physiol Biochem 2018;49:2254-2263

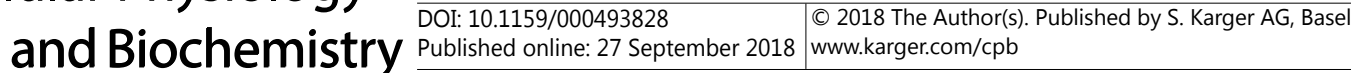 \\ Zhang et al.: Hyperglycemia Promotes Cardiac Stem Cell Adipogenesis}

In brief, cells were mixed with cytoplasmic protein extraction buffer, vortexed at maximum speed, and then incubated for $15 \mathrm{~min}$ on ice. After centrifugation at $12,000 \times g$ for $5 \mathrm{~min}$ at $4^{\circ} \mathrm{C}$, the suspension was discarded. Then, the nuclear protein extraction buffer was added to the pellet and vortexed at maximum speed. After incubation for $30 \mathrm{~min}$ on ice, the suspension was centrifuged for $5 \mathrm{~min}$ at $4^{\circ} \mathrm{C}$ at $12,000 \times g$. The supernatant comprised the nuclear fraction, which was immediately harvested and stored at $-80^{\circ} \mathrm{C}$.

\section{Immunofluorescence staining}

Cells were fixed in $4 \%$ paraformaldehyde/PBS for 20 min, permeabilized with $0.2 \%$ TritonX-100/ PBS for $10 \mathrm{~min}$, and then rinsed with PBS and immersed in blocking solution containing $1 \%$ bovine serum albumin (BSA) and $0.3 \%$ Triton X-100 for $30 \mathrm{~min}$. Cells were incubated overnight at $4{ }^{\circ} \mathrm{C}$ with polyclonal antibodies against $\beta$-catenin (\#8480; 1:1000; Cell Signaling Technology, Danvers, MA) and TCF-4 (ab76151; 1:300; Abcam Inc., Cambridge, MA). After washing three times, cells were incubated with DyLight 488 goat anti-rabbit (green, 1:200, Abbkine, Wuhan, China) secondary antibody, then observed and photographed using an inverted fluorescence microscope (Nikon, Tokyo, Japan).

\section{Adipogenesis induction, flow cytometry, and western blot analysis}

CSCs were treated with adipogenesis induction medium (20\% Mesen Cult TMA dipogenic Stimulatory Supplement in serum-free medium, STEMCELL Technologies, Vancouver, Canada) for 2 weeks with medium changed every 2 to 3 days. After fat induction, CSCs were cultured with fluorochrome-conjugated primary antibodies against c-Kit, Sca-1, MDR-1, isl-1, PPAR $\gamma$, ADD1, and C/EBP $\alpha$ (Santa Cruz Biotechnology, Inc., Dallas, TX) to determine the effects of high glucose on CSC differentiation by flow cytometry using the Becton-Dickinson FACSCaliber with 10, 000 events collected.

For western blot analysis, CSCs were lysed in RIPA buffer $25 \mathrm{mmol} / \mathrm{L} \mathrm{Tris-HCl} \mathrm{pH} \mathrm{7.6,150} \mathrm{mmol} / \mathrm{L} \mathrm{NaCl}$, $1 \%$ NP-40, 1\% deoxycholate, $1 \%$ Triton X-100, 0.5\% sodium dodecyl sulfate, $2 \mathrm{mmol} / \mathrm{L}$ EDTA, $0.5 \mathrm{mmol} / \mathrm{L}$ phenylmethylsulfonyl fluoride, protease inhibitor cocktail). Protein was quantified using Bio-Rad protein assay reagents (Bio-Rad Laboratories, Hercules, CA). Equal amounts of protein were separated using 10\% sodium dodecyl sulfate-polyacrylamide gel electrophoresis and then transferred to polyvinylidene fluoride membranes (Millipore, Billerica, MA). Blocking was performed at room temperature with 5\% nonfat milk powder prepared in tris-buffered saline containing $0.1 \%$ Tween 20 (TBST) for $1 \mathrm{~h}$, and then the membranes were incubated overnight at $4^{\circ} \mathrm{C}$ with the primary antibodies. Primary antibodies against Wnt11 (ab31962; 1:300; Abcam Inc.) and PPAR $\gamma$ (SC-7273; 1:500, Santa Cruz Biotechnology, Inc.) were incubated at $4^{\circ} \mathrm{C}$ in TBST supplemented with 3\% BSA. After washing three times with TBST for $10 \mathrm{~min}$, blots were incubated with infrared-labeled secondary antibody (Li-COR Biosciences, Lincoln, NE). Image J software (National Institutes of Health, Bethesda, MD) was used to quantify the band intensity after normalization relative to $\beta$-actin.

\section{Adipogenesis induction with or without LiCl treatment and Oil Red O staining}

$\mathrm{LiCl}$ (20 mM) solution (Sigma-Aldrich, St. Louis, MO) was added to IMDM containing 10\% FBS. CSCs at $80 \%$ confluence were treated with $20 \mathrm{mM} \mathrm{LiCl}$ in 9000 or 18, $000 \mathrm{mg} / \mathrm{L}$ glucose diluted in IMDM for 72 $\mathrm{h}$. In the control group, $80 \%$ confluent CSCs were exposed to IMDM containing 10\% FBS for $72 \mathrm{~h}$ before adipogenesis induction.

Adipocyte differentiation was assessed by cell morphology and specific staining of lipid droplets with Oil Red O (Amresco, Solon, OH). The cells were stained with $0.3 \%$ Oil Red O diluted in 60\% isopropanol and simultaneously the CSCs were dyed with hematoxylin (Sigma-Aldrich). Stained lipid droplets were viewed under a light microscope and photographed (Olympus, Tokyo, Japan) at $\times 400$ magnification. Oil Red 0 stain was dissolved in 2-propanol (Sinopharm Chemical Reagent Co., Ltd, Shanghai, China) and optical density was measured at $520 \mathrm{~nm}$.

\section{Statistical analysis}

All data are presented as the means \pm SEM. One-way analysis of variance with Student's-NewmanKeels test was used for statistical comparison when appropriate. $P$-values less than 0.05 were considered statistically significant. GraphPad Prism (GraphPad Prism Software, Inc., La Jolla, CA) was used for all statistical analyses. 


\section{Results}

\section{Characteristics of CSCs}

The CSCs showed a typical morphology with a spindle-like shape and strong refraction under light microscopy (Fig. 1A). Flow cytometry analysis showed that the cells were positive for common stem cell markers (c-Kit, Sca-1, and MDR-1) and negative for hematopoietic (CD34) and endothelial (CD31) markers (Fig. 1B). Thus, we confirmed in this study that these cells were CSCs, as in our previous studies [20,21].

High glucose inhibited the nuclear translocation of $\beta$-catenin/TCF-4 in CSCs

The cellular localization and levels of both $\beta$-catenin and TCF-4 were examined separately by immunofluorescence staining and western blot analyses. Immunofluorescence staining showed that $\beta$-catenin and TCF- 4 were localized in the nucleus of CSCs in the control group. However, when treated with $9000 \mathrm{mg} / \mathrm{L}$ glucose, some CSCs showed a lack of $\beta$-catenin and TCF-4 nuclear translocation, which indicated that high glucose significantly inhibited the nuclear translocation of $\beta$-catenin and TCF-4 in CSCs $(P<0.05$; Fig. 2A, 2B). Western blot analysis of the nuclear fractions of cellular proteins also showed a significant decrease in the amount of nuclear $\beta$-catenin in the high-glucose group compared with the control group (Fig. 2D, $P<0.05$ ). Furthermore, decreased expression of TCF- 4 was observed in both groups (Fig. 2E, $P<0.05, \mathrm{P}<0.01$ ). However, compared with the control group, the amount of $\beta$-catenin or TCF-4 protein did not change in the 9000 and $18,000 \mathrm{mg} / \mathrm{L}$ mannitol groups. These findings suggested that high glucose suppressed the $\beta$-catenin/TCF4 signaling pathway in CSCs.

High glucose promoted adipogenic gene expression but decreased cardiogenic gene expression during fat induction

After 1 week of fat differentiation, flow cytometry was used to examine the levels of gene expression in CSCs with or without high glucose treatment. Our results showed that most CSCs expressed c-Kit, Sca-1, MDR-1, and isl-1 (cardiogenic transcription factors) and few CSCs expressed PPAR $\gamma, \mathrm{CEBP} / \alpha$, and ADD1 (adipogenic transcription factors) in the control 


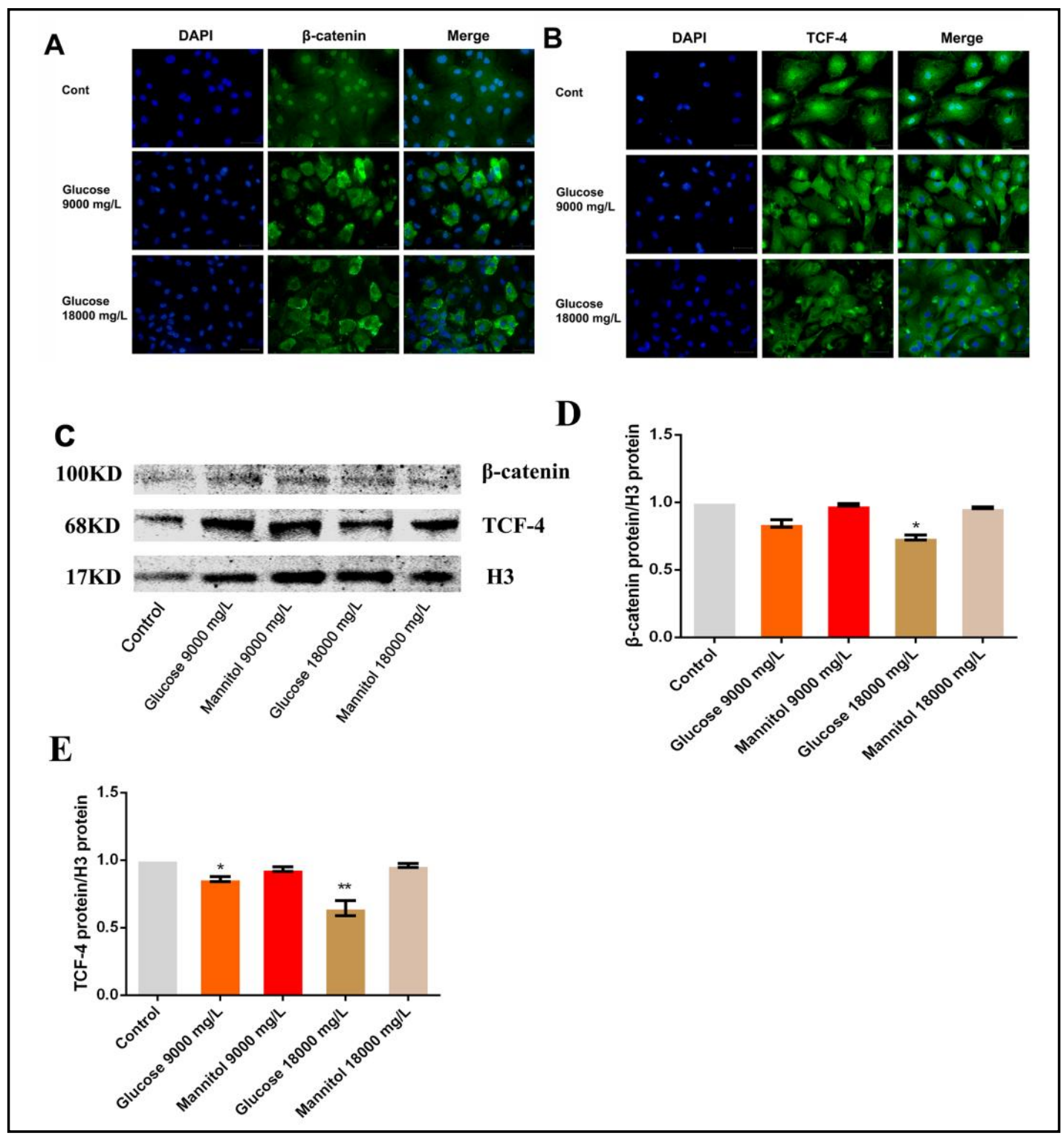

Fig. 2. High glucose inhibited nuclear translocation of $\beta$-catenin/TCF- 4 in CSCs. (A and B) CSCs were exposed to glucose ( 9000 and 18,000 mg/L) in IMDM containing 10\% FBS for $72 \mathrm{~h}$. Immunofluorescence staining was performed to determine the localization of $\beta$-catenin (A, green) and TCF- 4 (B, green). Note the significant lack of nuclear localization of $\beta$-catenin and TCF- 4 in the glucose $(18,000 \mathrm{mg} / \mathrm{L})$ treatment group (scale bar: $200 \mu \mathrm{m}$ ). (C) CSCs were treated with high glucose or mannitol for $72 \mathrm{~h}$ after adherence and then harvested for western blot analysis. (D and E) Corresponding densitometric analyses of the protein bands of (D) $\beta$-catenin and (E) TCF-4 measured in the immunoblots and normalized to the signal of H3. Data are presented as the mean $\pm \operatorname{SEM}(\mathrm{n}=3) ;{ }^{*} \mathrm{P}<0.05$, ${ }^{* *} \mathrm{P}<0.01$ vs control group.

group. After high-glucose treatment, the number of CSCs that expressed c-Kit, Sca-1, MDR-1, and isl-1 was considerably decreased. The number of CSCs that expressed ADD1, PPAR $\gamma$, and CEBP/ $\alpha$ was markedly increased following fat induction (c-Kit, $89.43 \pm 3.2 \%$ vs $38.8 \pm 3.2 \%$; Sca-1, 72.2 $\pm 2.7 \%$ vs $23.9 \pm 4.1 \%$; MDR-1, $78.1 \pm 0.35 \%$ vs $17.4 \pm 2.3 \%$; isl $-1,67.5 \pm 1.8 \%$ vs $17.1 \pm 4.3 \%$; PPAR $\gamma, 2.4 \pm 0.7 \%$ vs $40.7 \pm 6.5 \%$; ADD $1,1.1 \pm 0.3 \%$ vs $27.6 \pm 1.9 \%$; C/EBP $\alpha, 0.4$ $\pm 0.1 \%$ vs $19.5 \pm 2.2 \%$; all $P<0.01$, Fig. 3 ).

Western blotting analysis showed that the PPAR $\gamma$ expression level was significantly increased in the high-glucose group in a dose-dependent manner: in the $9000 \mathrm{mg} / \mathrm{L}$ glucose 


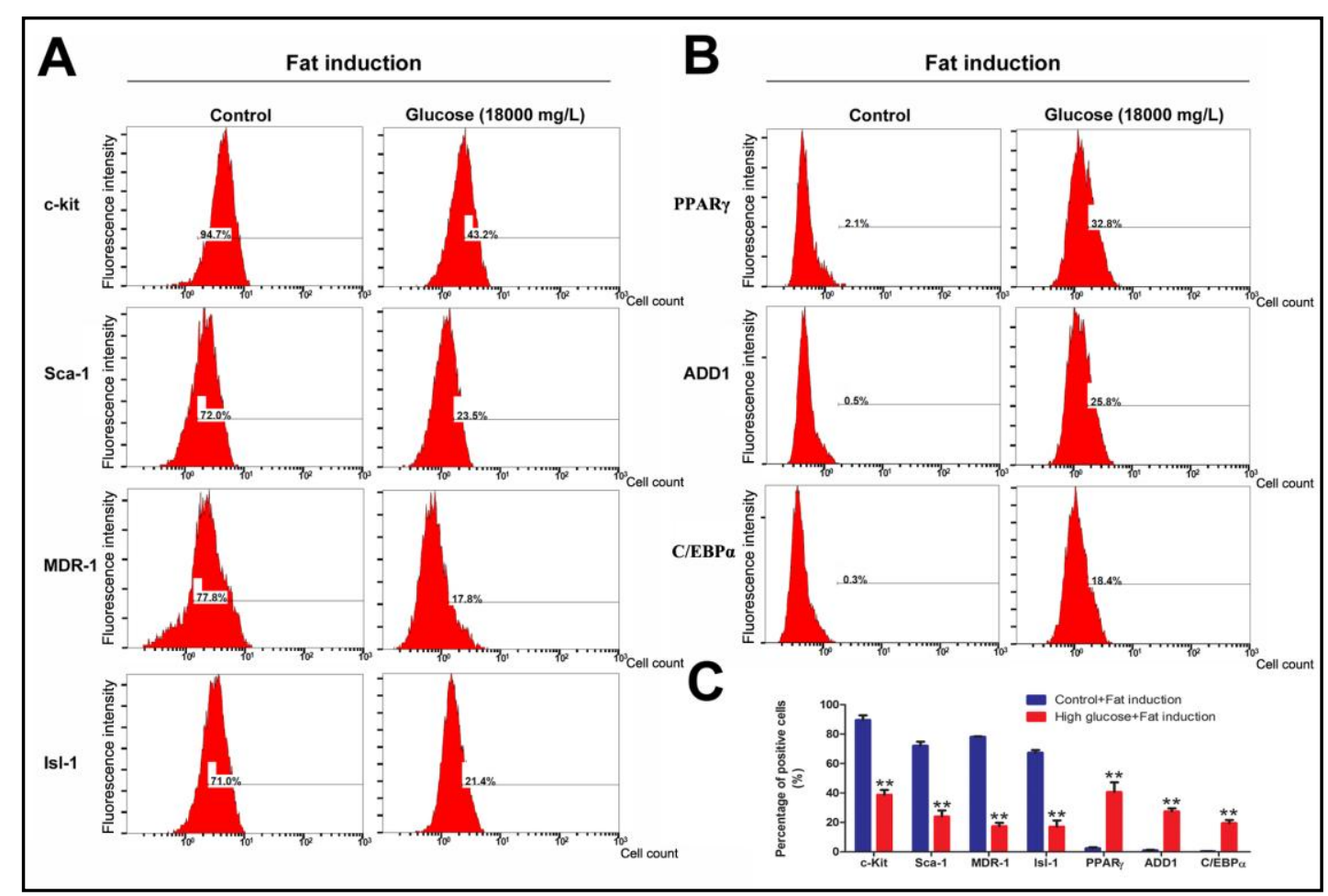

Fig. 3. High glucose decreased the expression of cardiogenesis gene transcripts but promoted adipogenesis gene transcripts during fat induction. CSCs were exposed to glucose $(18,000 \mathrm{mg} / \mathrm{L})$ diluted in IMDM containing 10\% FBS for $72 \mathrm{~h}$ before fat induction. After 1 week of fat induction, CSCs were analyzed by flow cytometry. (A) c-Kit, Sca-1, MDR-1, and isl-1 were decreased in the high-glucose treatment group, while (B) adipogenic transcription factors, namely, PPAR $\gamma, \mathrm{C} / \mathrm{EBP} \alpha$, and ADD1, were markedly increased by high-glucose treatment compared with the control group. (C) A representative experiment from three independent experiments is presented; results show the mean $\pm \operatorname{SEM}(\mathrm{n}=3) .{ }^{* *} \mathrm{P}<0.01$ vs control group.

group, it was increased to $2.02 \pm 0.21$-fold that in the control group, and in the $18,000 \mathrm{mg} / \mathrm{L}$ glucose group, it was increased to $3.56 \pm 0.25$-fold that in the control group (both $P<0.01$ ). The expression level of Wnt11 was significantly decreased in the high-glucose group: in the $9000 \mathrm{mg} / \mathrm{L}$ glucose group, it was decreased to $0.91 \pm 0.06$-fold that in the control group, and in the $18,000 \mathrm{mg} / \mathrm{L}$ glucose group, it was decreased to $0.61 \pm 0.05$-fold that in the control group (both $P<0.01$, Fig. 4). The expression level of PPAR $\gamma$ was slightly increased in the mannitol group $(2.40 \pm 0.36$-fold that in the control group, $P<0.01)$, while the expression levels of Wnt11 were not significantly lower in the mannitol group compared with the control group (1.15 \pm 0.11 -fold that in the control group, $P>0.05$, Fig. 4$)$.

\section{High glucose promotes adipogenesis in CSCs during fat induction}

Next, adipogenesis of CSCs during fat induction was measured by Oil Red 0 staining to determine whether CSCs were more likely into differentiate to adipocytes in a high-glucose microenvironment (Fig. 5A). After 2 weeks of fat induction, fewer CSCs differentiated into adipocytes in the control group. In the $9000 \mathrm{mg} / \mathrm{L}$ glucose group, adipogenesis was significantly increased compared with the control group $(P<0.01$, Fig. 5B), and Oil Red 0 staining in the $18,000 \mathrm{mg} / \mathrm{L}$ glucose group showed more lipid accumulation compared with the control group $(P<0.01$, Fig. 5B). However, when treated with $\mathrm{LiCl}$, the degree of adipogenesis in the $9000 \mathrm{mg} / \mathrm{L}$ glucose group was decreased significantly compared with the corresponding cells without $\mathrm{LiCl}(P<0.01$, Fig. 5B). The results were similar to those in the $18,000 \mathrm{mg} / \mathrm{L}$ glucose group both with and without LiCL $(P<0.01$, Fig. $5 \mathrm{~B})$. 
Fig. 4. High glucose (A) increased the expression of PPAR $\gamma$ but (B) decreased the expression of Wnt11 after 1 week of fat differentiation. (C, D) The expression levels of Wnt11 and PPAR $\gamma$ were determined by western blot analysis. A representative experiment from three independent experiments

is presented; results show the mean \pm SEM ( $\mathrm{n}=5$ ). ${ }^{*} \mathrm{p}<0.05$, ${ }^{* *} \mathrm{P}<0.01$ vs control

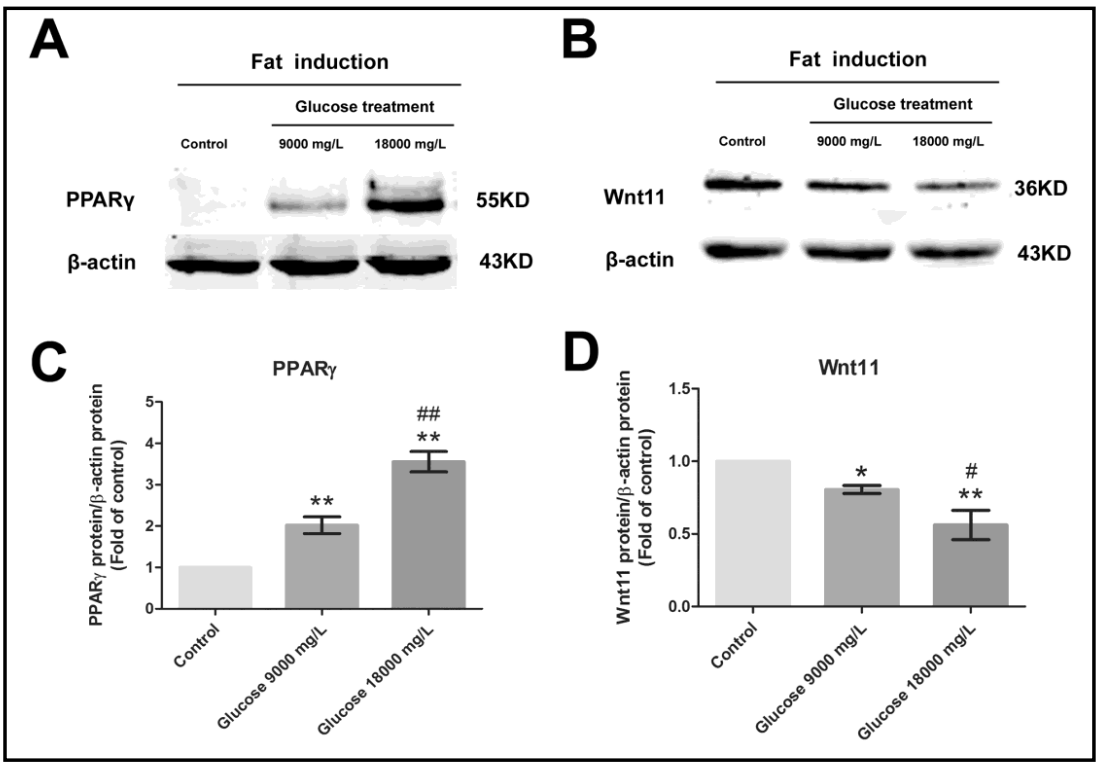
group; ${ }^{\mathrm{P}}<0.05,{ }^{\# \#} \mathrm{P}<0.01$ vs $9000 \mathrm{mg} / \mathrm{L}$ glucose treatment group.

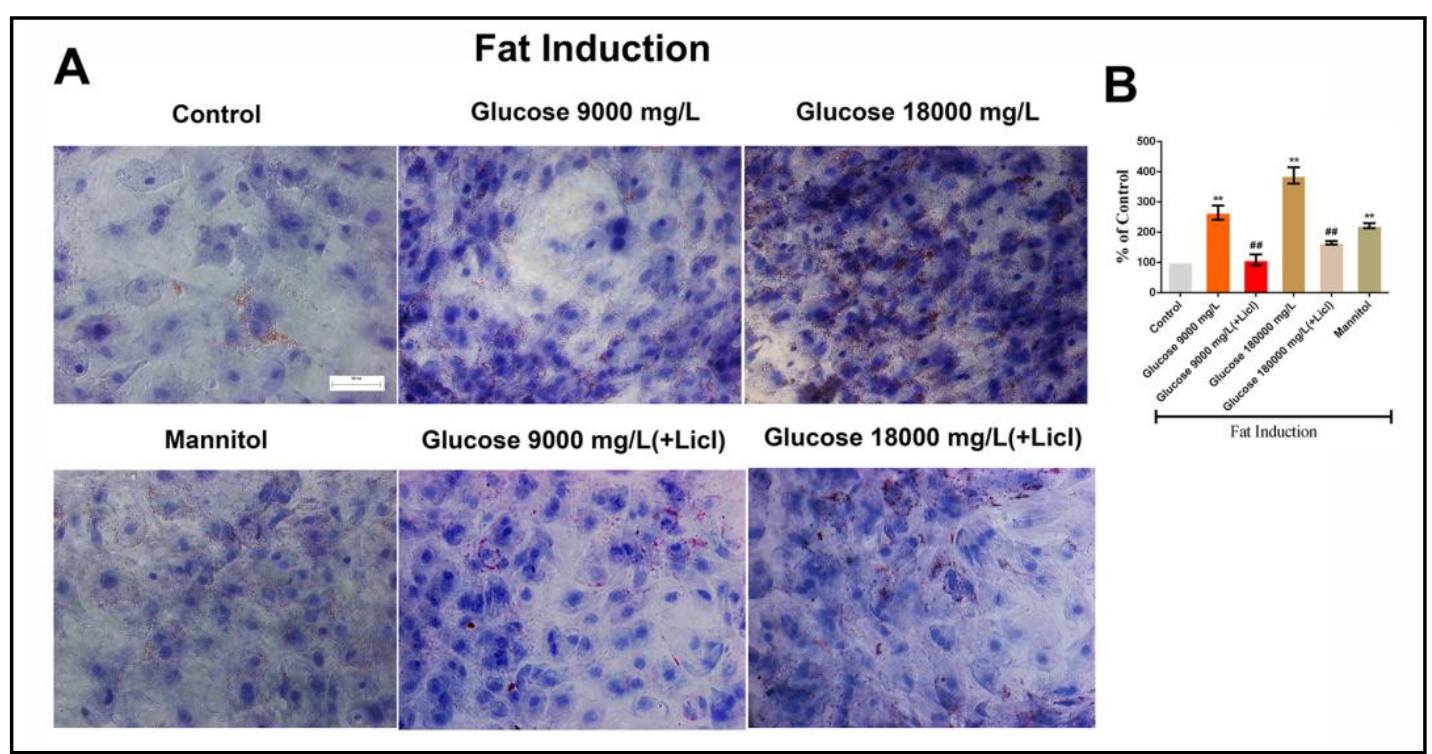

Fig. 5. (A) High glucose promoted adipogenesis in CSCs. CSCs were exposed to glucose (9000 and 18,000 $\mathrm{mg} / \mathrm{L}$ ) diluted in IMDM (with or without LiCL) containing 10\% FBS for $72 \mathrm{~h}$ before fat induction. Mannitol $(18,000 \mathrm{mg} / \mathrm{L})$ was used as a control for osmotic pressure. After 2 weeks of differentiation, intracellular lipid was stained with Oil Red $O$ and the nucleus was stained with hematoxylin. Scale bars: $50 \mu \mathrm{M}$. (B) Quantification of lipid accumulation based on Oil Red 0 staining on day 14. The proportion of Oil Red $O$ staining in each treatment group relative to the control group. Data are presented as the mean \pm SEM $(n=$ 5 ); ${ }^{* *} \mathrm{P}<0.01$ vs control group; ${ }^{\#} \mathrm{P}<0.01$ vs glucose 9000 or $18,000 \mathrm{mg} / \mathrm{L}$ treatment group.

\section{Discussion}

Recent autopsy findings demonstrated that diabetes significantly increases myocardial lipid deposition. The increase in myocardial adipose tissue is a part of the diabetic cardiomyopathy process $[24,25]$. Furthermore, in the presence of hyperglycemia, the myocardium was more vulnerable and more difficult to repair [26, 27]. However, the mechanism underlying hyperglycemia-induced poor myocardial regeneration and increased 


\section{Cellular Physiology Cell Physiol Biochem 2018;49:2254-2263

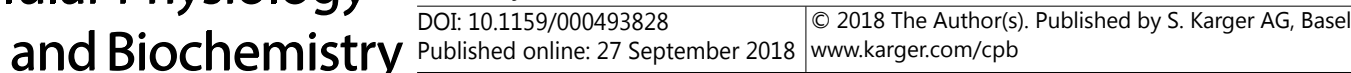 \\ Zhang et al.: Hyperglycemia Promotes Cardiac Stem Cell Adipogenesis}

epicardial fat in diabetes remains unknown. To our knowledge, the present results demonstrated for the first time that high glucose inhibited nuclear translocation of $\beta$-catenin / TCF-4, promoted the expression of adipogenic transcriptional factors (PPAR $\gamma$, ADD1, and c/ EBP $\alpha$ ), and suppressed CSCs markers (c-Kit, Sca-1, MDR-1, and isl-1), eventually increasing lipid droplet formation during fat induction of CSCs.

Canonical Wnt signaling inhibits adipogenesis by stabilizing $\beta$-catenin. In the absence of Wnt stimulation, cytoplasmic $\beta$-catenin is phosphorylated by a multiprotein that targets $\beta$-catenin for ubiquitination and proteasomal degradation. Wnt ligands promote the dissociation of this destructive complex and thereby prevent $\beta$-catenin from degradation, which results in cytoplasmic $\beta$-catenin accumulation and translocation into the nucleus where $\beta$-catenin co-activates the T-cell factor (TCF)/lymphoid enhancer factor family of transcription factors to inhibit adipogenesis [28-30]. TCF-4, also known as transcription factor 7 like-2, is an important transcription factor that triggers the downstream responsive genes of WNT signaling [31]. Hence, the Wnt/ $\beta$-catenin signaling pathway, which suppresses adipocyte differentiation, is a molecular adipogenesis switch [29]. The present results demonstrated that hyperglycemia inhibited nuclear translocation of $\beta$-catenin to induce adipogenesis, while the presence of $\mathrm{LiCl}$, a potent activator of TCF/ $\beta$-catenin-dependent transcription [32], attenuated adipogenesis under high-glucose conditions. Furthermore, the induction of adipogenesis was consistent with the downregulation of both Wnt and $\beta$-catenin.

The results of immunofluorescence staining and flow cytometry analysis were consistent with suppression of the $\beta$-catenin/TCF-4 pathway in CSCs with induction of adipogenesis. Following fat induction and high-glucose treatment, CSCs could activate three principal regulators of terminal adipogenesis: $\mathrm{PPAR} \gamma, \mathrm{C} / \mathrm{EBP} \alpha$, and ADD1. In mammalian cells, these factors are considered to be the key early regulators of adipogenesis [33]. Here, our results suggested that CSCs treated with high glucose could decrease CSC markers (c-Kit, Sca-1, MDR-1, and isl-1) and increase adipogenic transcription factors (PPAR $\gamma$, ADD1, and C/EBP $\alpha$ ). We also demonstrated that wnt11 expression decreased while PPAR $\gamma$ expression increased, indicating that CSCs had a tendency toward adipogenesis but not cardiac differentiation as Wnt-11 is a regulator of noncanonical Wnt signaling in cardiogenesis [34]. Furthermore, after 2 weeks of adipogenesis induction, Oil Red 0 staining showed that, following highglucose treatment, CSCs are more likely to differentiate into adipocytes and demonstrate an increase in lipid droplet formation. Interestingly, $\mathrm{LiCl}$ attenuated the adipogenesis effect of high glucose and reduced lipid droplet formation after adipogenesis induction.

\section{Conclusion}

The present results demonstrated that hyperglycemia significantly suppressed the nuclear translocation of $\beta$-catenin/TCF- 4 and promoted adipogenesis in CSCs of the diabetic heart. Our findings also indicated that CSCs could differentiate into adipocytes, increase epicardial fat, and reduce the pool size of functionally competent CSCs, reduce myocardial regeneration in diabetes. These results provide a possible explanation for abnormal regeneration capability and epicardial fat in the diabetic heart.

\section{Acknowledgements}

The authors thank Ms. Zahraa.Sh.Hmood (School of Medicine, Zhejiang University) and Ms. Daijuanru Wang (Zhejiang University-University of Edinburgh Institute) for proofreading the manuscript. The authors also thank Dr. Sanhua Fang for professional secretarial services. This study was supported by the Zhejiang Provincial Natural Science Foundation of China (No. LY18H170002) and the National Natural Science Foundation of China (No. 81472149, 81871541 and No. 81471837). 


\section{Cellular Physiology Cell Physiol Biochem 2018;49:2254-2263 \begin{tabular}{ll|l} 
and Biochemistry & $\begin{array}{l}\text { DOI: 10.1159/000493828 } \\
\text { Published online: } 27 \text { September } 2018\end{array}$ & $\begin{array}{l}\text { @ } 2018 \text { The Author(s). Published by S. Karger AG, Basel } \\
\text { www.karger.com/cpb }\end{array}$ \\
\hline
\end{tabular}

Author contributions: Xiaoming Zhang, Ke Meng, and Yujie Pu performed the experiments; Chao Wang, Yingying Chen, and Linlin Wang analyzed the data; and Xiaoming Zhang, Yingying Chen, and Linlin Wang designed the study and wrote the paper.

\section{Disclosure Statement}

The authors have no conflicts of interest to declare.

\section{References}

1 Chakrabarti AK, Singh P, Gopalakrishnan L, Kumar V, Elizabeth Doherty M, Abueg C, Wang W, Gibson CM: Admission hyperglycemia and acute myocardial infarction: outcomes and potential therapies for diabetics and nondiabetics. Cardiol Res Pract 2012;2012:704314.

2 Liang H, Vallarino C, Joseph G, Manne S, Perez A, Zhang S: Increased risk of subsequent myocardial infarction in patients with type 2 diabetes: a retrospective cohort study using the U.K. General Practice Research Database. Diabetes Care 2014;37:1329-1337.

- S Shah AM, Hung CL, Shin SH, Skali H, Verma A, Ghali JK, Kober L, Velazquez EJ, Rouleau JL, McMurray JJ, Pfeffer MA, Solomon SD: Cardiac structure and function, remodeling, and clinical outcomes among patients with diabetes after myocardial infarction complicated by left ventricular systolic dysfunction, heart failure, or both. Am Heart J 2012;162:685-691.

4 Gaborit B, Kober F, Jacquier A, Moro PJ, Cuisset T, Boullu S, Dadoun F, Alessi MC, Morange P, Clement K, Bernard M, Dutour A: Assessment of epicardial fat volume and myocardial triglyceride content in severely obese subjects: relationship to metabolic profile, cardiac function and visceral fat. Int J Obes (Lond) 2011;36:422-430.

5 Iacobellis G, Barbaro G, Gerstein HC: Relationship of epicardial fat thickness and fasting glucose. Int J Cardiol 2008;128:424-426.

-6 Brinkley TE, Leng X, Chughtai HL, Nicklas BJ, Kritchevsky SB, Ding J, Kitzman DW, Hundley WG: Periaortic fat and cardiovascular risk: a comparison of high-risk older adults and age-matched healthy controls. Int J Obes (Lond) 2014;38:1397-1402.

7 Levelt E, Pavlides M, Banerjee R, Mahmod M, Kelly C, Sellwood J, Ariga R, Thomas S, Francis J, Rodgers C, Clarke W, Sabharwal N, Antoniades C, Schneider J, Robson M, Clarke K, Karamitsos T, Rider O, Neubauer S: Ectopic and Visceral Fat Deposition in Lean and Obese Patients With Type 2 Diabetes. J Am Coll Cardiol 2016;68:53-63.

8 Chhabra L, Gurukripa Kowlgi N: Cardiac adipose tissue: Distinction between epicardial and pericardial fat remains important! Int J Cardiol 2015;201:274-275.

-9 Levit RD, Landazuri N, Phelps EA, Brown ME, Garcia AJ, Davis ME, Joseph G, Long R, Safley SA, Suever JD, Lyle AN, Weber CJ, Taylor WR: Cellular encapsulation enhances cardiac repair. J Am Heart Assoc 2013;2:e000367.

10 Angert D, Berretta RM, Kubo H, Zhang H, Chen X, Wang W, Ogorek B, Barbe M, Houser SR: Repair of the injured adult heart involves new myocytes potentially derived from resident cardiac stem cells. Circ Res 2011;108:1226-1237.

-11 Ellison GM, Vicinanza C, Smith AJ, Aquila I, Leone A, Waring CD, Henning BJ, Stirparo GG, Papait R, Scarfo M, Agosti V, Viglietto G, Condorelli G, Indolfi C, Ottolenghi S, Torella D, Nadal-Ginard B: Adult c-kit(pos) cardiac stem cells are necessary and sufficient for functional cardiac regeneration and repair. Cell 2013;154:827842 .

12 Bulatovic I, Mansson-Broberg A, Sylven C, Grinnemo KH: Human fetal cardiac progenitors: The role of stem cells and progenitors in the fetal and adult heart. Best Pract Res Clin Obstet Gynaecol 2015;31:58-68.

13 Saravanakumar M, Devaraj H: Distribution and homing pattern of c-kit+ Sca-1+ CXCR4+ resident cardiac stem cells in neonatal, postnatal, and adult mouse heart. Cardiovasc Pathol 2013;22:257-263.

14 Tzahor E, Poss KD: Cardiac regeneration strategies: Staying young at heart. Science 2017;356:1035-1039. 


\section{Cellular Physiology Cell Physiol Biochem 2018;49:2254-2263 \begin{tabular}{l|l|l} 
DOI: 10.1159/000493828 & (c) 2018 The Author(s). Published by S. Karger AG, Basel
\end{tabular} and Biochemistry Published online: 27 September 2018 www.karger.com/cpb \\ Zhang et al.: Hyperglycemia Promotes Cardiac Stem Cell Adipogenesis}

15 Gianfranceschi G, Caragnano A, Piazza S, Manini I, Ciani Y, Verardo R, Toffoletto B, Finato N, Livi U, Beltrami CA, Scoles G, Sinagra G, Aleksova A, Cesselli D, Beltrami AP: Critical role of lysosomes in the dysfunction of human Cardiac Stem Cells obtained from failing hearts. Int J Cardiol 2016;216:140-150.

16 Mayfield AE, Tilokee EL, Davis DR: Resident cardiac stem cells and their role in stem cell therapies for myocardial repair. Can J Cardiol 2014;30:1288-1298.

17 Zhang Y, Sivakumaran P, Newcomb AE, Hernandez D, Harris N, Khanabdali R, Liu GS, Kelly DJ, Pebay A, Hewitt AW, Boyle A, Harvey R, Morrison WA, Elliott DA, Dusting GJ, Lim SY: Cardiac Repair With a Novel Population of Mesenchymal Stem Cells Resident in the Human Heart. Stem Cells 2015;33:3100-3113.

18 Lang CI, Wolfien M, Langenbach A, Muller P, Wolkenhauer O, Yavari A, Ince H, Steinhoff G, Krause BJ, David R, Glass A: Cardiac Cell Therapies for the Treatment of Acute Myocardial Infarction: A Meta-Analysis from Mouse Studies. Cell Physiol Biochem 2017;42:254-268.

19 Molgat AS, Tilokee EL, Rafatian G, Vulesevic B, Ruel M, Milne R, Suuronen EJ, Davis DR: Hyperglycemia inhibits cardiac stem cell-mediated cardiac repair and angiogenic capacity. Circulation 2014;130:S70-76.

20 Zhang L, Geng WR, Hu J, Chen XM, Shen YL, Wang LL, Jiang JP, Chen YY: Lipopolysaccharide pretreatment promotes cardiac stem cell migration through heat shock protein 90-dependent beta-catenin activation. Life Sci 2016;153:132-140.

21 Liu W, Pu Y, Wang C, Gu C, Zhang X: Expression profiles of long noncoding RNAs in cardiac stem cells under hyperglycemic conditions. Int J Cardiol 2016;222:933-939.

22 Urbanek K, Torella D, Sheikh F, De Angelis A, Nurzynska D, Silvestri F, Beltrami CA, Bussani R, Beltrami AP, Quaini F, Bolli R, Leri A, Kajstura J, Anversa P: Myocardial regeneration by activation of multipotent cardiac stem cells in ischemic heart failure. Proc Natl Acad Sci U S A 2005;102:8692-8697.

23 Qyang Y, Martin-Puig S, Chiravuri M, Chen S, Xu H, Bu L, Jiang X, Lin L, Granger A, Moretti A, Caron L, Wu X, Clarke J, Taketo MM, Laugwitz KL, Moon RT, Gruber P, Evans SM, Ding S, Chien KR: The renewal and differentiation of Isl1+ cardiovascular progenitors are controlled by a Wnt/beta-catenin pathway. Cell Stem Cell 2007;1:165-179.

24 Nakanishi T, Kato S: Impact of diabetes mellitus on myocardial lipid deposition: an autopsy study. Pathol Res Pract 2014;210:1018-1025.

25 Yang YK, Chen M, Clements RH, Abrams GA, Aprahamian CJ, Harmon CM: Human mesenteric adipose tissue plays unique role versus subcutaneous and omental fat in obesity related diabetes. Cell Physiol Biochem 2008;22:531-538.

26 She T, Wang X, Gan Y, Kuang D, Yue J, Ni J, Zhao X, Wang G: Hyperglycemia suppresses cardiac stem cell homing to peri-infarcted myocardium via regulation of ERK1/2 and p38 MAPK activities. Int J Mol Med 2012;30:1313-1320.

27 Busche MN, Walsh MC, McMullen ME, Guikema BJ, Stahl GL: Mannose-binding lectin plays a critical role in myocardial ischaemia and reperfusion injury in a mouse model of diabetes. Diabetologia 2008;51:15441551.

28 Wang L, Di LJ: Wnt/beta-Catenin Mediates AICAR Effect to Increase GATA3 Expression and Inhibit Adipogenesis. J Biol Chem 2015;290:19458-19468.

-29 Ross SE, Hemati N, Longo KA, Bennett CN, Lucas PC, Erickson RL, MacDougald OA: Inhibition of adipogenesis by Wnt signaling. Science 2000;289:950-953.

-30 Choi OM, Cho YH, Choi S, Lee SH, Seo SH, Kim HY, Han G, Min DS, Park T, Choi KY: The small molecule indirubin-3'-oxime activates Wnt/beta-catenin signaling and inhibits adipocyte differentiation and obesity. Int J Obes (Lond) 2013;38:1044-1052.

-31 Chen ZL, Shao WJ, Xu F, Liu L, Lin BS, Wei XH, Song ZL, Lu HG, Fantus IG, Weng JP, Jin TR: Acute Wnt pathway activation positively regulates leptin gene expression in mature adipocytes. Cell Signal 2015;27:587-597.

32 Xia MY, Zhao XY, Huang QL, Sun HY, Sun C, Yuan J, He C, Sun Y, Huang X, Kong W, Kong WJ: Activation of Wnt/beta-catenin signaling by lithium chloride attenuates d-galactose-induced neurodegeneration in the auditory cortex of a rat model of aging. FEBS Open Bio 2017;7:759-776.

-33 Feng X, Liu X, Cai X, Lin T, Xu W, Yang C, Liu Y, Yang S, Fu D: The Influence of Tetracycline Inducible Targeting Rat PPARgamma Gene Silencing on the Osteogenic and Adipogenic Differentiation of Bone Marrow Stromal Cells. Curr Pharm Des 2016;22:6330-6338.

-34 Flaherty MP, Dawn B: Noncanonical Wnt11 signaling and cardiomyogenic differentiation. Trends Cardiovasc Med 2008;18:260-268. 